\title{
A experiência vanguardista proposta por Oliverio Girondo em Veinte Poemas Para Ser Leídos en El TranVía
}

\section{La experiencia vanguardista propuesta por Oliverio Girondo en Veinte Poemas Para Ser Leídos en El Tranvía}

\author{
Marina de Freitas Fortes
}

\section{RESUMO}

20 poemas para ser leídos en el tranvía, de Oliverio Girondo, é a primeira obra do autor, publicada em meio ao fervor das vanguardas, em 1922. O livro apresenta-se como uma verdadeira experiência sensorial, que se desvela em frente ao leitor por meio da composição dos textos, de forma original e inovadora. O presente trabalho tem como propósito, portanto, analisá-lo sob a perspectiva de buscar compreender de que forma se dá a criação do olhar vanguardista de Girondo. Para isso, são abordados três poemas representativos da obra, "Rio de Janeiro", "Milonga" e "Pedestre", nos quais se estuda de que forma o espaço e a linguagem são utilizados nos versos e de que modo estes se unem às ilustrações caricaturais do autor para restabelecer a relação entre palavra e visualidade e proporcionar essa vivência única ao leitor.

PALAVRAS-CHAVE: Oliverio Girondo; vanguarda hispano-americana; poesia; ilustração

\section{RESUMEN}

20 poemas para ser leídos en el tranvía, de Oliverio Girondo, es la primera obra del autor, publicada en medio del fervor de las vanguardias, en 1922. El libro se presenta como una verdadera experiencia sensorial, que se desvela al lector por medio de la composición de los textos, de una forma original e innovadora. Así, el presente trabajo tiene como propósito analizarlo bajo la perspectiva de búsqueda por la comprensión de la forma de creación de la mirada vanguardista de Girondo. Para eso, son abordados tres poemas representativos de la obra, "Rio de Janeiro", "Milonga" y "Pedestre", en los cuales se estudia de qué forma el espacio y el lenguaje son utilizados en los versos y de qué modo esos se juntan con las ilustraciones caricaturescas del autor para que se restablezca la relación entre la palabra y la visualidad y proporcione esa vivencia única al lector.

PALABRAS CLAVE: Oliverio Girondo; vanguardia hispanoamericana; poesía; ilustración

O livro Veinte poemas para ser leídos en el tranvía, de Oliverio Girondo, foi publicado no ano de 1922: trata-se de um projeto vanguardista, em que a maneira de encarar e transfigurar o conteúdo poético é bastante pessoal e muitos dos recursos que o autor viria radicalizar nos próximos livros já podem ser encontrados neste primeiro de sua carreira. A epígrafe "Ningún 
prejuicio más ridiculo, que el prejuicio de lo sublime" (ONETTI, 1922, p. 11) anuncia que o autor não se limitará ao que se entende por sublime, elevado, destinado naturalmente ao fazer poético, nem no que diz respeito à temática e nem no que tange ao vocabulário: tudo pode ser utilizado para a poesia, desde que articulado segundo a sua maneira.

No título é que se dá entrega a respeito do direcionamento a que se deve submeter o olhar para a leitura dos poemas. A instrução para que os textos sejam lidos no bonde, em realidade, é muito mais poética do que prática, e reflete o fato de que a impressão de mundo registrada é semelhante ao olhar de um indivíduo que, no bonde, não tem tempo para observar demoradamente e pensar acerca do que vê; ademais, a ideia de estar num bonde pressupõe que os temas podem ser retirados da realidade. Assim, o que se encontra na obra é uma experiência sensorial - e por vezes até mesmo sensual - do mundo em sua imediatez e assombro.

Além disso, os poemas de Veinte poemas... são como textos de viagem: as cidades se manifestam frente ao poeta, que as escreve - e que não somente as escreve, como também desenha, uma vez que o livro é composto por dez ilustrações realizadas pelo próprio Girondo: "em Oliverio há um grande pintor e ao mesmo tempo um grande escritor ${ }^{1}$ " (SCHWARTZ, 2013, p.115). A força imagética da obra, porém, não se limita aos desenhos em meio aos poemas, que, na realidade, devem ser lidos em conjunto com a construção textual, restabelecendo a relação entre visualidade e palavra.

Em “Rio de Janeiro”, por exemplo, o texto é precedido pela ilustração reproduzida ao lado, em que é possível observar características da cidade num traço colorido e caricatural: estão presentes os morros ao fundo, típicos do relevo carioca, assim como as casas simples que compõem as favelas - já então parte do espaço urbano - de forma pouco realista e distorcida. O poema, que apresenta versos livres, se abre dizendo que a cidade imita o cartão: a ordem das coisas é, logo de saída, subvertida, uma vez que o cartão-postal é que normalmente retrata a cidade, ao invés de servir-lhe de modelo. Os elementos que compõem essa cidade-cartão, entretanto, não são estáticos como numa fotografia: as caravanas são compostas por montanhas, que acampam nos arredores; o Pão de Açúcar perderá o equilíbrio pela falta de uma sombrinha de papel; os prédios, dotados de rostos, se apresentam como num espetáculo circense, antecipado já pelo equilibrista figurado na sombrinha de papel, e fazem acrobacias a cidade, sempre em movimento, se demonstra através da antropomorfização da paisagem.

${ }^{1}$ Ramon Gómez de la Serna, citado por Jorge Schwartz em "Fervor das Vanguardas", p. 115. 


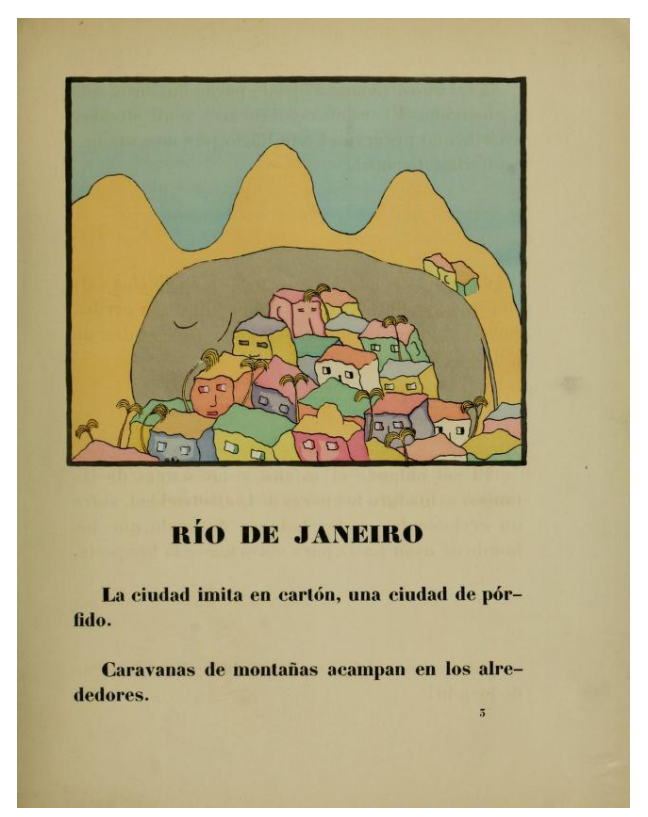

Fonte: 20 poemas para ler no bonde. Edição Brasileira. (GIRONDO, 2014).

Os verbos e as relações entre as coisas não estão estabelecidos conforme a linguagem cotidiana os emprega: o experimento da vanguarda se transmite pela quebra de expectativa as ruas são regadas pela água de jasmim, o sol sofre um crepúsculo, as montanhas acampam em caravanas, os edifícios saltam uns em cima dos outros; as velhas árvores são apresentadas como pederastas e tragam às crianças que brincam, as frutas são responsáveis por causar buracos ao cair, o sorriso do negro é representado por uma melancia, a luz é uma pera madura da eletricidade. Nada está empregado conforme o usual, tudo é inusitado.

Os botões das calças dos homens, as nádegas femininas e as peras, unidos na mesma frase pela presença da luz, compõem a ideia geométrica de forma circular, dando um aspecto quase tridimensional ao texto. $\mathrm{O}$ uso do contraste entre as cores retoma a visualidade e se faz presente, por exemplo, na descrição dos negros que apresentam pele de tabaco, palma das mãos feitas de corais, e sorriso de melancia - as mãos e o sorriso contrastando em relação à pele escura. A experiência sensorial é reforçada ainda pela presença do olfato, que entra em cena por meio do perfume de água de jasmins que rega a rua e que retorna ao fim do poema, através do cheiro de café que, por quatrocentos mil-réis, é capaz de perfumar todo um bairro durante dez minutos. Os sentidos são saturados pela cidade, que é entregue por Girondo de forma fragmentada e brincalhona: tudo atrai a visão do visitante e, portanto, tudo é posto em questão; tudo é extraordinário e, portanto, é descrito como extraordinário.

Em "Milonga", o primeiro aspecto proporcionado pela leitura é, por sua vez, o da fragmentação: isto porque, visualmente falando, o poema é atravessado pela imagem de um homem tocando um bandoneón (abaixo), que somente será aludido pela escrita no segundo parágrafo. O título, como em "Rio de Janeiro", também faz referência a um espaço: aqui, não mais o exterior da cidade, mas um salão de baile - ambiente tipicamente argentino e, portanto, igualmente característico da cidade de que se escreve, Buenos Aires. Não é possível saber 
exatamente o que se narra: por linhas gerais, porém, é possível deduzir que se trata de uma confusão. De todo modo, a forma como isso é narrado é que nos interessa.

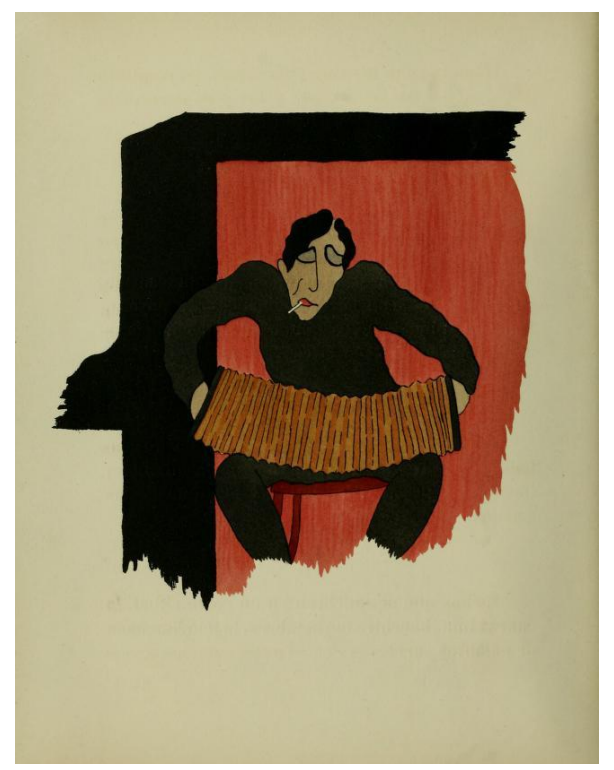

Fonte: 20 poemas para ler no bonde.

Edição Brasileira. (GIRONDO, 2014).

O poema se abre com a imagem de garrafas de champanhe decapitadas, descritas de forma humanizada, vestindo gravatas e cujos "braços" e "costas" apoiam-se nos baldes de níquel que as transportam - a decapitação, por si só, é a forma de morte que melhor transmite a fragmentação do corpo, ao separar o órgão de comando dos demais. Na segunda estrofe, "el bandoneón" atrai com sua canção os mamilos, as púbis e as pontas de sapatos dos que escutam; os indivíduos são, então, representados metonimicamente, de forma que a ideia de desmembramento se reforça. A quebra surge ainda na terceira estrofe, no verso "Machos que se quiebran en un corte ritual”, antes da cisão principal, provocada pela imagem. A ideia de “corte ritual”, porém, é produzida pelas palavras vulgares aprisionadas na boca, que incham bochechas: é, portanto, o silêncio que produz a quebra (que pode se referir até mesmo à interrupção da conversação).

Após a ilustração, o texto retorna com a animalização feminina, em contraste com a humanização do champanhe no início: a mulher é representada enquanto fêmea de ancas nervosas, axilas espumantes e olhos azeitados. A atmosfera de certa violência não se reduz frente à presença de desejo (também expresso pela música e, até certo ponto, pelas palavras vulgares), sendo transmitida também pela adjetivação da mulher. É somente na quinta estrofe, porém, que seu ápice se apresenta:

De pronto se oye un fracaso de cristales. Las mesas dan un corcovo y pegan cuatro patadas en el aire. Un enorme espejo se derrumba con las columnas y la gente que tenía dentro; mientras entre un oleaje de brazos y de espaldas estallan las trompadas, como una rueda de cohetes de bengala. (ONETTI, 1922, p. 31) 
O vocabulário é, como em "Rio de Janeiro", notavelmente utilizado fora do contexto usual - fator que vai ser reproduzido em todos os poemas do livro. As taças e mesas são associadas a termos utilizados, normalmente, para seres vivos: “fracaso", “corcovo", "pegan en el aire”. Os seres vivos, pelo contrário, são novamente descritos metonimicamente, por meio de braços e costas que esmurram como "uma rueda de cohetes de bengala". Há uma alteração na ordem das coisas produzida por esse contraste de tratamento, que, unida à impressão de fragmentação obtida pela estrutura, reforçam a ideia de confusão e briga. O conflito condensase no trecho acima, com a destruição do ambiente ao estraçalhar cristais, virar mesas ao revés, derrubar espelhos, colunas e gente (que se estapeia); mas já está, como visto, posto desde o início do poema. O fechamento, entretanto, vem em forma apaziguadora: "Junto con el vigilante, entra la aurora vestida de violeta" (ONETTI, 1922, p. 31). O dia, vestido de violeta, acompanha o vigilante, que encerrará o conflito - violência e desejo ficam, assim, contidos no espaço da noite a que são tradicionalmente associados.

Em "Pedestre", como em "Milonga", o lugar assinalado ao fim do poema é Buenos Aires, porém, como em "Rio de Janeiro", o poeta retorna ao espaço externo, à rua. O título faz referência a um indivíduo que, porém, não é aludido durante o texto, o que possibilita a pressuposição de que o olhar proposto é o do pedestre. A ilustração - um farol de iluminação reforça a modernidade do espaço urbano. Novamente, há antropomorfização de edifícios, sombras, faróis, quiosques... A cidade é, para Girondo, um organismo vivo, capaz de proporcionar as mais diversas experiências.

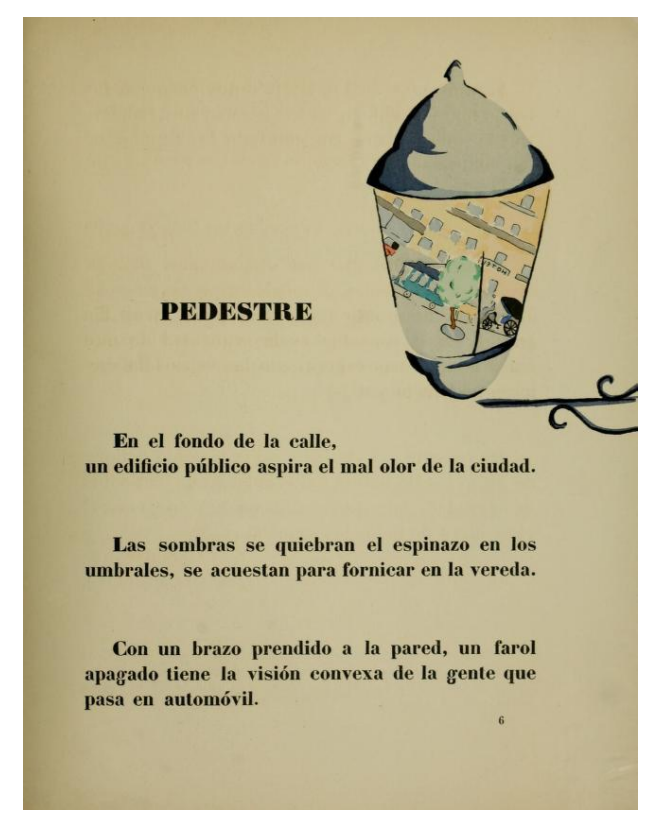

Fonte: 20 poemas para ler no bonde.

Edição Brasileira. (GIRONDO, 2014).

O primeiro parágrafo dá início à descrição do cenário a que o olhar do leitor terá acesso: uma rua, localizada em uma cidade cujo cheiro, ao contrário de "Rio de Janeiro", não é 
agradável. $\mathrm{O}$ aspecto sensual entra em pauta logo em seguida, no segundo parágrafo, quando "sombras se quiebran el espinazo en los umbrales, se acuestan para fornicar en la vereda" (ONETTI, 1922, p. 49) - não são as pessoas que se cruzam, mas sim suas sombras, que se sobrepõem pela vereda; trata-se de um verso extremamente visual. $O$ farol que compõe a ilustração é então descrito pelo uso de características humanas, como o "braço" que o prende à parede, simbolizando a estrutura metálica, e a visão que ele tem das pessoas que passam de automóveis.

A mirada do farol, entretanto, parece mais digna do que o olhar dos transeuntes, uma vez que esses sujam as ruas com seu olhar - os elementos urbanos são, deste modo, privilegiados pelo autor em relação às pessoas. Os quiosques tragam mulheres; a inglesa é idêntica ao farol; o bonde, que leva alunos, é descrito como um colégio sobre rodas; o cachorro é associado à ideia de fracasso, pelos olhos de prostituta, mulher a que se dá vergonha em olhar. A visão caricatural de Girondo inova a forma de entrega dos elementos poéticos, transfigurando-os segundo a lógica pessoal.

Há ainda, nesse poema, uma nota em relação ao cão, descrevendo o que se entende por cães fracassados: "Los perros fracasados han perdido a su dueño por levantar la pata como una mandolina, el pellejo les ha quedado demasiado grande, tienen una voz afónica de alcoholista y son capaces de estrarse en un umbral, para que los barran junto con la basura" (ONETTI, 1922, p. 49). Não somente a voz afônica dos cachorros, porém, é que se assemelha à dos alcoólatras, mas toda a situação descrita é análoga. A despersonalização dos indivíduos proposta pelo autor neste e em outros poemas permite que se leia cães enquanto representação do grupo de bêbados, portanto.

O fechamento do texto, como em "Milonga”, vem com a presença do vigilante, que aqui se apresenta enquanto maestro da cidade, calando os estremecimentos para que se possa ouvir um único som: o sussurro dos seios ao se roçarem - o mundo em seu apelo sensual.

A métrica, como é possível perceber através dessa amostragem, não é uma preocupação em Girondo: seus versos livres traduzem melhor a liberdade de perambular pela cidade. Algumas imagens - como os edifícios vivos, o vigilante, o aroma das ruas - são recorrentes e o olhar fragmentário atravessa toda a obra, como um fio condutor. O vocabulário é, a todo o momento, subvertido, e o colorido das imagens divide, lado a lado, o espaço com a violência, a sensualidade e a modernidade. "Veinte poemas para ser leídos en el tranvia", assim, traduz o espírito vanguardista com formas que nenhum de seus contemporâneos foi capaz de equiparar. A originalidade da epifania visual de sua escrita leva o leitor a repensar o ambiente cosmopolita e a, de fato, se deixar guiar pelas ruas das cidades no bonde em cujo maquinistaautor distorce os planos e proporciona experiências que, de outra forma, são inacessíveis. Ler o primeiro livro de Oliverio Girondo é, portanto, uma experiência única. 


\section{Referências bibliográficas}

GIRONDO, Oliverio. 20 poemas para ser leídos en el tranvía. Buenos Aires: La Facultad, 1922.

SCHWARTZ, Jorge. "Ver/ler: o júbilo do olhar em Oliverio Girondo". In: Fervor das vanguardas, Arte e literatura na América Latina. São Paulo: Companhia das Letras, 2013.

PORTUGAL, Rúben Vargas. "Veinte poemas para ser leídos en el tranvia, Calcomanías y otros poemas”. In: Los libros. Edição e notas de Trindade Barreira. Madrid: Visor, 1989, p. 194.

BITTENCOURT, Rita Ienira de Freitas. "Rio de Janeiro". In: A poética espacial da vanguarda argentina: uma cidade, p. $124-128$. 